\title{
The Psychological Hardiness of Students with a High Insomnia Index During the Covid-19 Pandemic
}

\author{
Dmitry Totskiy ${ }^{1, *}$, Anatoly Alekhin ${ }^{2}$, Natalia Leonenko², Christina Pultcina $^{2}$, Svetlana \\ Belyaeva $^{2}$, and Lubomir Guzi ${ }^{3}$ \\ ${ }^{1}$ Don State Technical University, Ploshchad' Gagarina, 1, 344002 Rostov-on-Don, Russia \\ ${ }^{2}$ Russian State Pedagogical University A.I. Herzen, Embankment river Moyka, 48, 191186 St. \\ Peterburg, Russia \\ ${ }^{3}$ Presov University, 17. novembra 3724/15, 08001 Presov, Slovakia
}

\begin{abstract}
The combination of total uncertainty and forced self-isolation during the pandemic create a condition for stress reactions, mental and somatic disturbance of a large number of people around the world. Sleep quality has been validated as an indicator of well-being during a pandemic and a predictor of delayed risk. At this article demonstrate the interaction between psychological hardness and risk of insomnia in group of students of Herzen University during the period of remote education connected with COVID-19 pandemic. The hypothesis of the study was the assumption about the influence of hardness on the ability of students to cope with the challenge of complexity, the negative relationship of its characteristics with the index of insomnia and anxiety, as well as positive ones with the characteristics of life-meaning orientations and tolerance to uncertainty. The study show that level of psychological hardness can predict risk of insomnia and feeling of anxiety. The article demonstrate that psychological hardiness is connected with tolerance to the uncertainty. The practical significance is determined by the substantiation of indicators of potential risk and directions of development of resources for coping with the challenge of complexity in the student period. The article shows that resilience is associated with a tolerance for uncertainty.
\end{abstract}

\section{Introduction}

The pandemic announced by the World Health Organization (WHO) on March 11, 2020 in connection with the rapid spread of coronavirus - SARS-CoV-2 [1], has become one of the most serious challenges to humanity in its history. The stressfulness of the situation is associated with a number of factors, among which are the indefinite duration of a lifethreatening situation, the restriction of freedom due the quarantine, the uncertainty of the incubation period of a viral infection, the possibility of its asymptomatic transmission [2]. The lack of information about the new infection, predictions for the spread and experience of coping with it, results in the mental problems in the population.

\footnotetext{
*Corresponding author: 1971-fireman@mail.ru
} 
During the COVID-19 pandemic, the phenomenon of the absence of visible sources threat gave rise to the polar strategies for coping with the stress of uncertainty - denial of danger and over-control of the situation. The denial can increase the risk of physical infection. The overcontrol becomes a source of acute stress with the subsequents such post-traumatic stress disorder, sleep disorders and other clinical and psychological disorders. At the same time, copings, which in normal conditions helps to overcome stress situations (seeking social support and activity, etc.), in a situation of forced self-isolation become inaccessible.

The danger of the situation connected with prolonged nature of this stress factors. The theory and practice of stress psychology testifies to the ability of the individual to maximize the mobilization of his own resources during the period of the acute stress situation (pandemic), but in parallel this period of acute mobilization during of the increasing and exhausting of opportunities, an acute delayed reaction can developed. Prolongation can last up to two years, after which and over the next 10 years, a person is still experiencing the effects of stress [3]. The nature of the negative influences is not always obvious, therefore, the search for indicators reflecting the objective state of the subject during this period seems to be practically significant from the point of view of the development psychological treatment to prevent delayed reactions.

An analysis of the researches published during the pandemic showed that already in February 2020, Chinese experts recorded signs of mental distress in $70 \%$ of respondents, signs of generalized anxiety disorder in $35.1 \%$, depression in $20.1 \%$, sleep disorders in $18.2 \%$ respondents [4]. Failure to cope with stress at the psychological level provide the risk of negative changes in vegetative and humoral regulation and some somatic consequence. One of the most common symptom of the stress associated with sleep disturbances [4]. On ICD 10 insomnia define as a sleep disorder associated with difficulties in initiating or maintaining sleep and "a deficiency in the quality and quantity of sleep necessary for normal daytime activities" [5]. Sleep quality disorders have a serious negative impact on mental and somatic health, life expectancy [6]. As sleep problems can increase the risk of social disadaptation, mood disorders, daytime sleepiness, decreased performance, self-limiting behavior, expressed in a narrowing of the range of habitual actions, increases. Thus, insomnia is a psychophysiological problem which decrease the quality of life [7].

High practical relevance of the research of individual characteristics of coping with stress in sleep disorders and without it is connected with identification of ways to maintain mental and somatic health. This problem becomes even more urgent in relation to the student period, which is characterized by increased stressfulness even outside the pandemic. Another important fact that determines the specifics of this period is the social situation of the adolescences development, determined by the tasks of professional, social and personal selfdetermination, the success of which determines the quality of further development, the possibility of self-realization. The age-related difficulties of the student period in a pandemic situation are aggravated by the distance learning.

In the question of psychological resources for coping with stress associated with a pandemic, we proceed from the idea that such conditions can create specific stress conditions. The specificity of the negative impact of the pandemic, as shown above, is determined by a combination of two factors - total uncertainty and forced self-isolation, frustrating basic human needs for safety and freedom. The first becomes a trigger of existential experiences, the second, as a result of limiting external activity and external resources, drivers a person to turn to himself in search of an internal point of support and certainty. The phenomenon of uncertainty in the 21 st century is starting to interest not only for psychologist, but also for the other scientist. In related sciences, the methodology of this issue was developed in the works of I.R. Prigogine, R. Harre, E. Giddens, U. Beck, E. Morena, N.N. Taleb and others. In modern psychology this phenomenon is investigated in the psychology of uncertainty (D. Kahneman, I.M. Feigenberg, etc.), the psychology of social instability (G.V. Soldatova), the 
personology of maladaptive behavior (A.V. Petrovsky), the psychology of self-organization of psychological systems (V.E. Klochko), the psychology of complexity (A.N. Poddyakov) [8]. In existential psychology, uncertainty is defined as a borderline situation and the result of coping with which depends on the efforts expended by the individual [9]. K. Jaspers claims that ability to find the meaning of the life is the main predictor of post-traumatic growth.

In the activity approach the semantic self-regulation is described through the struggle of motives, in which the subordination of incentive motives depends on the individual's efforts (A.N. Leontiev). The role of personal efforts in development is reflected in the concept of "zone of proximal development" (L.S. Vygotsky) [10]. Both phenomena suppose the ability to overcome the difficulty definite by mastering new skills. In the theory of activity of A.N. Leontiev, the semantic regulation of personality development is reflected in the phenomenon of the conflict of motives, in which the subordination of incentive motives to the semantic ones depends on the efforts of the individual and, therefore, the individual's output to a proactive mode of functioning versus a reactive one. In M. Chinksetmihalyi's concept of flow, the relationship between the individual's efforts and its evolution is described through the desire to repeat the state once experienced after successfully solving a problem on the verge of its performance. But the tasks of the previous level of complexity no longer provide needed level of difficulty and it is become necessary to increase the degree of complexity to expand the zone of proximal development.

The psychology of optimal coping under conditions of uncertainty described in the concept of hardiness, introduced by Salvador Maddi. Hardiness is understood by the author as the ability of a person to the self-regulation at the somatic and psychological levels, which allows regulating mental and physical health, reducing internal stress due to persistent coping with stress and the perception of stress factors as less significant [11]. In an existential level, hardiness is correlated with the category self-affirmation of being in spite of the threats ( $\mathrm{P}$. Tiillich), including loneliness and illness (May R.). In conditions of total uncertainty, when the patterns habitual for controlled conditions do not have time to adequately adapt to rapid changes of the situation the core ability becomes the opportunity to take the feedback from these changes. The idea of self-regulation based on feedback methodologically originates in the concept of physiology of activity by N.A. Bernstein and brings resilience from the category of adaptation to the level of oversituational activity and transadaptation. This level correlates with the psychologically mature personality, "who perceives reality as total uncertainty and enters into a dialogue with the world and other people to verify this picture [12]. Hardiness as the ability for such mature forms of self-regulation, in comparison with adaptation, has a disproportionately large number of degrees of freedom, which means a large number of choices in a situation of uncertainty, orients towards openness to new experience, frees from the fear of change, contributes to a more objective assessment of the situation, which means and a more adequate response to it.

At the somatic level hardiness, is manifested in minimizing the destructive effect of stressors on the human body by maintaining the usual level of activation for a person and its provides an optimal level of neuropsychological processes (Maddy, 1987). If stress resistance defines as a measure of ability to overcome stress factors, then hardiness is a way of perceiving and processing stressful influences that provide this resistance. The buffer role of attitudes to the problem (attitudes) in psychological and somatic well-being is convincingly shown in studies of the psychological and somatic consequences of stress factors on the example of the professional activities of EMERCOM employees [13-14]. This study allows us to describe the strategies of reactions to stress situation in group of subjects with high hardiness, as transformation from impulsive behavior to control, from reactivity to selfregulation, from depletion of adaptive resources to coping. The role of hardiness in increasing the negative somatic consequences of stressful influences was experimentally confirmed in the study of A.A. Zemskova, N.A. Kravtsova [15]. The authors have established significant 
interaction between indicators of hardiness and balance of the sympathetic and parasympathetic nervous systems, stability of reactions, speed of visual-motor reaction. The data obtained indicate the role of hardiness in the subject's implementation of self-regulation at the level of both somatic reactions and specific actions.

In comparison with adaptation, hardiness has a large degrees of freedom, which means a number of choices in a situation of uncertainty. If adaptation is aimed to maintain the balance, then hardiness, is going beyond the usual balance through active transformation of the situation, a form of oversituational activity, that is called transadaptation (S. Maddi, D.A. Leontiev, etc.). Psychological adaptation in the case of extreme stress can lead to the mental maladjustment, which has been shown in a number of studies. Hardiness determines the ability of the individual development and reflected in reactions to frustration, which do not demonstrate losing of balance and becomes more and more complex "in response to the growth of uncertainty, complexity and diversity" [16].

Hardiness and coping are related in terms of proactivity and reactivity reaction to the stress. Hardiness as coping include transformational (S. Maddy) or proactive components (S. Taylor, R. Schwarzer, E. Greenglass, etc.), which determines the perception of a future stressful event as a challenge that requires a response, focuses the individual's efforts on management of goals. Proactive coping is opposed to reactive coping, which R. Schwarzer characterizes as a strategy for minimizing damage and losses. Thus, hardiness as coping correlates with the semantic level of regulation, which activates person to the algorithm of actions. The semantic nature of hardiness reflects the subjective level of development (K.A. Abulkhanova, L.I. Antsyferova, A.V. Brushlinsky, E.A. Sergienko).

Thus, the value of the concept of hardiness is determined by its systemic nature, including all levels of human functioning - mental, psychological, social and existential. Semantic content is a stable regulator of behavior that determines the forms and the possibility of coping at all other levels. The mechanisms that ensure the priority of the value-semantic and target formations of the personality in the regulation of the lower levels are described in the concepts of the existential-humanistic and activity approaches of psychology. Kurt Lewin describes such a model through volitional behavior directed by goals and contrasting it to the field behavior as a reaction to the force effects of the field. Volitional behavior allows a person to rise above the situation, based on their own ideas about the desired future. The lack of goals leaves a person under the influence of the situational influences of the field. Accordingly, the practical understanding of his life by a person from the point of view of the formation of goals and their implementation is already a mechanism and condition of psychological stability in relation to external influences. In A. Maslow's theory of motivation, the connection of the field (reactive) and volitional (proactive) levels is reflected in two ways of personality existence - deficit and existential. In the first type the main motivation of behavior is the desire to reduce stress from the frustration of any need. The second one is existential, it takes the personality beyond the limits of personal needs to the level of selfactualization, universal values and meanings. The first way is connected with balance protection, maintaining a comfort zone, and eliminating deficits. The second way is connected with situation of imbalance that gives an ability for constant growth and the acquisition of new qualities, the realization of the potential of the individual, the transformation of oneself and the world. These ideas substantiate the value of development, risk taking, involvement in the life process as key guidelines in the development of programs for psychological support of a person. Viktor Frankl describes such a way of life in terms of the noetic dimension experienced by a person as an inner spiritual force and as a source of motivation, born of striving for meaning. In this dimension, values, conscience, faith, responsibility, a sense of humor, inspiration, the ability to rise above the situation, and evaluate it as if from the outside are localized, which means to be free from this situation and act in accordance with our own decisions, and not stimuli. The provisions of V. Frankl's 
concept are the fundamental justification for the idea of the need to study and psychological influence on meaning as the core of hardiness. This means that if the person found the meaning of the life it can reconstructs the perception of reality and, accordingly, the reactions to the stress on the psychological and somatic level making the perception less traumatic, and the impact less destructive for the body and mental health.

The concepts of foreign psychologists bout driving and coping regulating are methodologically close to the fundamental principle of the activity approach about the unity of consciousness and activity (Leontiev A.N.). The activity aspect of hardness is realized in practical actions aimed at achieving the desired future (goal). Thus, the quality of the implemented activity is determined by the internal plan (the system of values and meanings of the individual). In relation to the model of activity the construct of hardness is a set of semantic attitudes and practices of their implementation, ensuring effective coping with difficult life situations at all levels. At the same time, based on the provisions discussed above, the existential level acts as an independent variable that determines the quality of functioning of all lower levels. The lower level - psychophysiological - reflects the resulting tendencies and, therefore, the indicators of mental activity can be considered as an objective assessment of systemic functioning.

We suggested that hardness is a predictor of successful resolution of an existential crisis in terms of not only maintaining mental and somatic health, but also gaining experience of deep self-improvement, personal strengthening and the potential to cope with life's difficulties. The systemic nature of this concept makes it possible to operationalize hardness in terms of life-meaning orientations and tolerance to uncertainty at the existential level, through the states that are relevant for the period under study - at the level of mental functioning.

On an empirical level the ability to cope with stress can be described by sleep quality which is both an indicator and a resource for coping with stress associated with a pandemic.

We hypothesized that level of hardiness connected the ability of the students to cope with stress in pandemic period and it will reflected into the level of insomnia.

\section{Materials and methods}

The study was conducted during the COVID-19 pandemic period from 06/01/2020 to 07/20/2020). The participants were recruited at the Institute of Psychology of the Herzen State Pedagogical University (Saint-Petersburg). The present study included 39 participants (mean age $=20.6$ y.o., $\mathrm{m}=15, \mathrm{f}=34$ ). The survey was conducted remotely via Google-forms. No personally identifiable information was stored in the collected data file.

The Google forms included the author's questionnaire and 5 psychometric methods. The questionnaire include socio-demographic characteristics and questions to identify the quality of changes during a pandemic in comparison with previous characteristics such as sleep, wellbeing, daily activity and emotional state. The presence and intensity of insomnia symptoms was assessed with The Insomnia Severity Index developed by Ch.Morin. To assess the level of hardness S. Maddy's Hardness test (adaptation D.A. Leontiev and E.I. Rasskazova) were used. The hardness test also include the general level of hardness and attitudes included in it: involvement, risk plan and control. Also were used the Multiple Stimulus Types Ambiguity Tolerance Scale-II and Test of life-meaning orientations (developed by D. Leontiev). To describe the current level of anxiety the the scale "Calmness - anxiety" of the L.V. Kulikov questionnaire "Actual state (AS)" were used. It makes possible to assess the parameters of the mental state in a short time interval, due to the influence of specific events, the current moment.

For data analysis Mann-Withey test, Pearson correlation test and linear regression were used. 


\section{Results}

The study of insomnia level in the group of students made it possible to establish that the majority of students have signs of insomnia, while both of the participants demonstrate moderate clinical manifestations of insomnia.

Table 1. The insomnia index in the group of students

\begin{tabular}{|c|c|c|c|}
\hline Level of insomnia & Quantity & $\begin{array}{c}\text { Mean } \\
\text { age }\end{array}$ & $\begin{array}{c}\text { Average } \\
\text { score }\end{array}$ \\
\hline $\begin{array}{c}\text { Severe clinical manifestations } \\
\text { of insomnia }\end{array}$ & $9(\mathrm{~m}=2, \mathrm{f}=7)$ & 20 & 27 \\
\hline $\begin{array}{c}\text { Moderate clinical } \\
\text { manifestations of insomnia }\end{array}$ & $27(\mathrm{~m}=10, \mathrm{f}=17)$ & 21 & 19 \\
\hline Borderline level of insomnia & $3(\mathrm{~m}=2, \mathrm{f}=1)$ & 20 & 13 \\
\hline
\end{tabular}

Comparative analysis of students with severe and moderate level of insomnia made it possible to establish significant differences in the scales of involvement $(U=3, p<0.000)$, control $(\mathrm{U}=41, \mathrm{p}=0.002)$, risk taking $(\mathrm{U}=1, \mathrm{p}<0.000)$, as well as the integral indicator of hardiness $(U=8.5, p<0.000)$ and the calm-anxiety scale $(U=16, p<0.000)$. An analysis of descriptive statistics allows us to conclude that group of participants with severe level of insomnia are associated with lower hardness, tend to be passive in decision making and helplessness, and tend to refuse to make decisions in the direction of safer ones (Table 2).

Analysis of life-meaning orientations showed significant differences between the groups with severe and moderate level of insomnia in the scales of life goals $(U=12, p<0.000)$, results orientation $(U=0.5, p<0.000)$, locus control of personal behavior $(U=2, p<0.000)$ and in locus control of life $(\mathrm{U}=22.5, \mathrm{p}<0.000)$.

The results of the study showed close relationship between the quality of sleep, hardness and the level of calmness of the students. To test this hypothesis, a regression analysis was performed. The integral score of insomnia was used as a dependent variable. The scales by the test of hardness and anxiety-calmness from the questionnaire of Actual mental states were used as the predictors.

Regression analysis demonstrate that variables such as hardness, involvement, control, risk taking and calmness explain about $85 \%$ of the variance in insomnia $(\mathrm{R} 2=0.856, \mathrm{~F} 5.33$ $=39.270$ ). So, the higher the hardness, involvement in activities, feeling of the life-control and the absence of fear in decision-making, the lower the integral level of insomnia (see Fig.1).

Indeed, it is impossible to make an unambiguous conclusion about the influence of the pandemic and distance learning conditions on the results obtained, however, of course, the more pronounced the indicators of hardiness, the easier person can cope with the stress. The research interaction between the anxiety and hardness showed that about $75 \%$ of the variance on the calm-anxiety scale is explained by hardness indicators $(\mathrm{R} 2=0.749, \mathrm{~F} 5.33=38.120)$. Thus, the lower the level of hardness, involvement and control, the higher the anxious experience. 
Table 2. Descriptive statistics of the groups with moderate and severe clinical level of insomnia

\begin{tabular}{|c|c|c|c|}
\hline $\begin{array}{l}\text { Name of the } \\
\text { methods }\end{array}$ & Scale & Insomnia level & $\mathrm{Me}$ \\
\hline \multirow{2}{*}{$\begin{array}{l}\text { Questionnaire of } \\
\text { Actual state (AS) }\end{array}$} & \multirow{2}{*}{$\begin{array}{l}\text { Calmness }- \\
\text { anxiety }\end{array}$} & Severe clinical manifestations of insomnia & 13.22 \\
\hline & & Moderate clinical manifestations of insomnia & 16.29 \\
\hline \multirow{8}{*}{$\begin{array}{l}\text { S. Maddy's } \\
\text { Hardness test }\end{array}$} & \multirow[t]{2}{*}{ Involvement } & Severe clinical manifestations of insomnia & 14.62 \\
\hline & & Moderate clinical manifestations of insomnia & 16.92 \\
\hline & \multirow[t]{2}{*}{ Control } & Severe clinical manifestations of insomnia & 14.66 \\
\hline & & Moderate clinical manifestations of insomnia & 16.22 \\
\hline & \multirow[t]{2}{*}{ Risk taking } & Severe clinical manifestations of insomnia & 7.55 \\
\hline & & Moderate clinical manifestations of insomnia & 11.8 \\
\hline & \multirow[t]{2}{*}{ Hardness } & Severe clinical manifestations of insomnia & 38.33 \\
\hline & & Moderate clinical manifestations of insomnia & 42.96 \\
\hline \multirow{10}{*}{$\begin{array}{l}\text { Test of } \\
\text { meaning } \\
\text { orientations }\end{array}$} & \multirow[t]{2}{*}{ Goals in life } & Severe clinical manifestations of insomnia & 37 \\
\hline & & Moderate clinical manifestations of insomnia & 35 \\
\hline & \multirow{2}{*}{$\begin{array}{l}\text { Orientation to } \\
\text { the process }\end{array}$} & Severe clinical manifestations of insomnia & 25 \\
\hline & & Moderate clinical manifestations of insomnia & 25 \\
\hline & \multirow{2}{*}{$\begin{array}{l}\text { Orientation to } \\
\text { the results }\end{array}$} & Severe clinical manifestations of insomnia & 21 \\
\hline & & Moderate clinical manifestations of insomnia & 23 \\
\hline & \multirow{2}{*}{$\begin{array}{ll}\text { Locus } & \text { of } \\
\text { control } & \text { of } \\
\text { personal } & \\
\text { behavior } & \\
\end{array}$} & Severe clinical manifestations of insomnia & 13 \\
\hline & & Moderate clinical manifestations of insomnia & 23 \\
\hline & \multirow{2}{*}{$\begin{array}{l}\text { Locus of } \\
\text { control of life }\end{array}$} & Severe clinical manifestations of insomnia & 25 \\
\hline & & Moderate clinical manifestations of insomnia & 18 \\
\hline \multirow{2}{*}{$\begin{array}{l}\text { Multiple Stimulus } \\
\text { Types Ambiguity } \\
\text { Tolerance Scale-II }\end{array}$} & \multirow{2}{*}{$\begin{array}{l}\text { Ambiguity } \\
\text { Tolerance }\end{array}$} & Severe clinical manifestations of insomnia & 44 \\
\hline & & Moderate clinical manifestations of insomnia & 28 \\
\hline
\end{tabular}

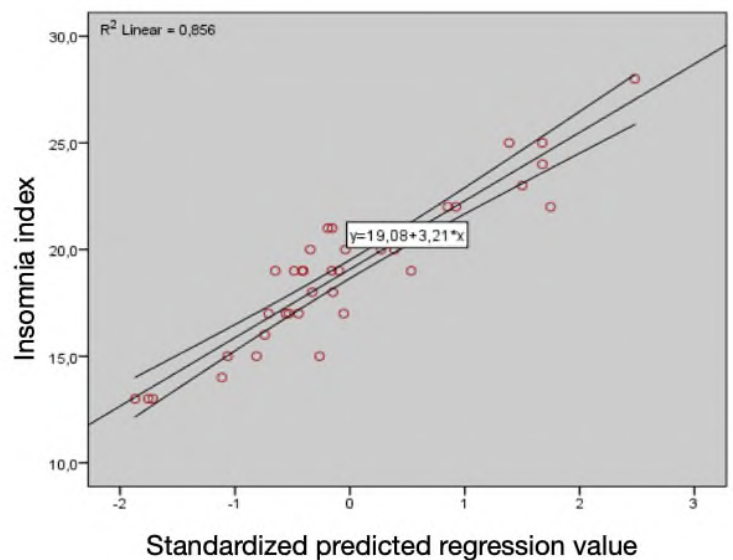

Fig. 1. Dependence of the level of insomnia on the integral indicator calculated according to the scales of the Hardness test and the scale of calmness-anxiety from the questionnaire of the Actual mental state 
Analysis of the correlation between the indicators of hardness, life-meaning orientations and the level of insomnia shows a negative correlation between the level of insomnia and the locus of control personal behavior $(\mathrm{r}=-0.594, \mathrm{p}<0.000)$, the locus of control life $(\mathrm{r}=$ $0.572, \mathrm{p}<0.000)$. The higher the confidence in the controll of life and own decisions and behavior, the lower the level of insomnia. Also, a negative correlation was found for the indicator of hardness and the presence of goals in life $(r=-0.794, p<0.000)$, so the fewer goals in life and plans a person has, the lower the hardness. It was demonstrate that high hardness is also associated with a personality's resistance to uncertainty $(r=0.695, p<0.000)$, as well as a sense of meaningfulness and effectiveness of life $(r=0.645, p<0.000)$.

\section{Discussion}

Summarizing the results of the study, we found that the clinical level of severity insomnia was recorded in the group of the students who are less involved in the life process, do not sufficiently control their actions and processes occurring in their life (possibly the phenomenon of learned helplessness). All this psychological factors becomes the basis for the development of persistent tension at all levels of functioning, which is reflected in quality of sleep, which is also a signal of systemic disturbance, and can lead to negative processes that reduce the ability to self-regulation and coping.

The study showed the difference in perception of time perspective in group with insomnia and without sleep disturbances. The participants without insomnia demonstrate more pronounced goals in life, reliance on the past experience and concentration on the present. Based on the theoretical concepts discussed above, we can assume that the integral wellbeing of students without sleep disturbances is connected with a balanced and meaningful time perspective. Reliance on the past and its comprehension, allows the participants to integrate and productively use individual experience in the present. The goals for the future set the vector of volitional behavior, which ensures the transition of functioning from the reflex level to the semantic level, which allows in a situation of negative influences to take a subjective position in relation to them. Involvement in the process of the present can be viewed in terms of a fully-functioning personality of Rogers' concept as the basis for an organismic assessment of the situation, that is, maximum sensitivity to signals from the external environment at all levels of functioning. This feeling provides the ability of the personality to change itself corresponding with external changes. This creates a stream, which an emotionally positive attitudes to the current situation and optimal motivation, on the other hand. Also, it creates a mechanism of development of the personality, under which forms of the self-regulation become more complicated. The idea of the resource role of the optimal motivation and maximum involvement in the life process is connected with the ideas about the development of the motivational sphere as a mechanism for the personality growth (A.N. Leontiev). Perhaps the including in the present life some significant interests create the conditions for dereflection, described by W. Frankl as a psychological mechanism that reduces the significance of traumatic influences by switching attention to positive aspects. The transformation of perception due to the transfer of focus from one object to another is similar to the law of the figure and the background described in Gestalt psychology. Perhaps these phenomena explain the transformation of the perception of a pandemic situation from a negative and threatening fact into a situation of discovering new resources. All these suggestion are confirmed by the relationships (negative between hardness and indicators of sleep quality and anxiety, positive between hardness and life-meaning orientations, calm state and tolerance to uncertainty) and in a high degree of variance, explaining the characteristics of hardness and sleep disturbance (85\%) and anxiety $(75 \%)$. In general, such model of explanation is correlate with the definition of the existential worldview as a criterion for the psychological maturity, which manifests in the perception of total uncertainty as a norm, in 
achieving certainty exclusively through one's own activity (according to D.A. Leontiev). With this level of psychological maturity, the situation of a pandemic and the uncertainty, loneliness, and lack of freedom associated with it is perceived as a resource. Anxiety is accepted in proportion equivalent to the situation, without spreading to uncontrollable aspects of life, stimulating the subject to be aware and act in relation to those aspects that can be controlled.

The analyzed characteristics of hardness of the students with a severity level of insomnia, reflect a low degree of stability and ability to cope with uncertainty at the level of attitudes (risk acceptance, tolerance to uncertainty) and actions (a low indicator of control, its locus of control personal behavior and life events). All this factor manifests in a feeling of helplessness and inability to influence on life events, the desire for safety and comfort, the perception of uncertainty as a threat. Mental states associated with this factor are also determined by the feeling of anxiety and a possible threat. As the results somatic and mental health disturbance can be observed.

According to studies conducted at the beginning of the pandemic (Hajduk, M. et al., p. 521 ), there has been no significant increase in the prevalence of mental disorders associated with the COVID-19 pandemic [20]. However, based on the delayed nature of the stress response, the peak in the prevalence of such disorders should be expected until early 2022. As the results of our study have shown, in the period June - July 2020, the overwhelming majority of respondents $(82.5 \%)$ in one way or another noted signs of insomnia, with $20 \%$ in severe and very severe degrees. Given the predictive nature of sleep quality in terms of somatic and psychological well-being, more than $80 \%$ have already entered the potential risk category.

In accordance with empirical data, the target model of psychological treatment should be based on the developing the characteristics of the hardness of students without clinical signs of insomnia during a pandemic. The analysis of the results of this study allows us to consider that the main directions of psychological treatment should be connected with increasing the meaningfulness of all life, actualizing past experience as a resource and finding meaning in the experienced situation, eventful and emotional experience of the present, setting goals for the future. In a situation of uncertainty that lead to anxiety, the semantic connection between a rich present and an unpredictable future makes it possible to transfer the fulcrum from the disturbing future to the fact that a person is able to control - his own reactions and behavior in the present. This transforms the perception of the situation from a catastrophic into a category of challenge, the response to which is a condition for the evolution of the personality, its complication due to the mastery of one's own mental functions, behavior at the level of semantic regulation.

\section{Conclusion}

Our study demonstrates the impact of hardness on the ability of students to cope with stressful factors connected with CoViD-19. There was found significant difference in hardness and its indicators between groups with severity and moderate insomnia. In this study was demonstrate positive correlation between the characteristics of hardness, life-meaning orientations and tolerance to uncertainty, about the presence The negative relationship between resilience, insomnia index and anxiety has received empirical confirmation. The results and our conclusions are correspondent with the concepts of semantic regulation of the personality at all levels of its functioning, of hardiness as a systemic ability of an individual to proactively cope and develop under stress conditions, the role of time perspective, procedurality and semantic regulation in maintaining the integrity of a frustrations formulated in line with the existential-humanistic direction of psychology, cultural-historical and activity approaches in Russian psychology. The results of the study are of practical importance from 
the point of view of substantiating the sleep quality as an integral indicator of the mental and somatic functioning and ability to cope with stress. These studies confirm the importance of the insomnia index in the prediction possible mental and psychological status and long-term risks. At the same time, the risk of insomnia can be predicted by the level of hardness, which is associated with time perspective and tolerance for uncertainty.

Considering the connection between hardness and the ability to integrate individual experience, and role of this factors in development at any stage of ontogenesis, starting from adolescence, make significant future similar studies on older age groups. In addition, it seems important to develop and test psychological programs for the development of psychological hardness for various age categories of the population.

\section{References}

1. World Health Organization (WHO) (Press release) Archived from the original on 11 March 2020 https://www.who.int/director-general/speeches/detail/who-directorgeneral-s-opening-remarks-at-the-media-briefing-on-covid-19---11-march-2020, (last accessed 2021/03/13)

2. M.Yu. Sorokin, E.D. Kasyanov, G.V. Rukavishnikov, et al.: The structure of anxious experiences associated with the spread of COVID-19: data from an online survey. Bulletin of the Russian State Medical University, 3, 77-84 (2020) DOI: 10.24075/vrgmu.2020.030 (last accessed 2021/03/13)

3. M.M. Reshetnikov, The non-evaluated challenges of the modern era. Psychological newspaper. Professional online edition (2020) https://psy.su/feed/8321, (last accessed 2021/03/13)

4. A.N. Alekhin, E.A. Dubinina, Pandemic: the view of a clinical psychologist. Arterial Hypertension, 26(3), 312-316 (2020) DOI: 10.18705/1607-419X-2020-26-3-312-316.

5. Yu.V. Bykhovets, M.V. Dan, D.A. Nikitina, International experience of research and practical recommendations to the population during Covid pandemic. Psychological newspaper. Professional online edition (2020) https://psy.su/feed/8378 (last accessed 2021/03/13)

6. https://icd.who.int/browse10/2016/en\#/F50.4, (last accessed 2021/03/13)

7. G.V. Kovrov, E.I. Rasskazova, M.A. Lebedev. Insomnia and impairment of daytime functioning. Medical Council, 12, 55-59 (2013)

8. A.G. Asmolov. Psychology of contemporary age: challenges of uncertainty, complexity and diversity. Psychological Researches, 40(8), 1 (2015)

9. R. Tedeschi, L. Calhoun. Posttraumatic Growth: Conceptual Foundations and Empirical Evidence. Psychological Inquiry, 15(1), 1-18 (2004)

10. N. Kornell, J. Metcalfe. Study efficacy and the region of proximal learning framework. Journal of Experimental Psychology: Learning, Memory, and Cognition, 32(3), 609-622 (2006) DOI: 10.1037/0278-7393.32.3.609

11. L.V. Kulikov, Psychology of mood (Saint-Petersburg, Izd-vo Sankt-Peterb. un-ta, 1997)

12. D.A. Leont'ev, E.N. Osin, E.G. Lukovitskaya. Diagnosis of Uncertainty Tolerance: D. McLean Scales (Moscow, Smysl, 2016)

13. Yu.Yu. Strelnikova. Types of psychological and somatic consequences arising in employees of the EMERCOM of Russia in the process of professional activity. Bulletin of the South Ural State University. Series: Psychology, 1(9), 55-63(2016) DOI: $10.14529 /$ psy 160106 
14. A.A. Bobrischev. Psychodiagnostic model for predicting personal resources of stressovercoming behavior of employees of the State Fire Service of the Ministry of Emergency Situations of Russia during the period of adaptation to professional activity. Scientific notes of the University P.F. Lesgaft, 2(132), 221-226 (2016) DOI: 10.5930/issn.1994-4683.2016.02.132.p221-226

15. A.A. Zemskova, N.A. Kravtsova. The program of increasing the resilience and psychological stability of cadets of the Ministry of Emergencies of Russia to extreme factors in the conditions of imitation of professional activity. Siberian psychological journal, 70, 42-58 (2018) DOI: 10.17223/17267080/70/4.

16. A.G. Asmolov, E.D. Shekhter, A.M. Chernorizov. Preadaptation to uncertainty: unpredictable evolutionary routes (Moscow, Akropol', 2018)

17. E.I. Rasskazova, A.Sh. Tkhostov. Insomnia Severity Index (Moscow, Smysl, 2012)

18. D.A. Leont'ev. Test of meaningful orientation (Moscow, Smysl, 1992)

19. D.A. Leont'ev, E.I. Rasskazova. Hardiness test (Moscow, Smysl, 2006)

20. M. Hajduk, D. Dancík, J. Januska. Psychotic experiences in student populationduring the COVID-19 pandemic. Schizophrenia Research, 222, 520-521 (2020) DOI: 10.1016 / j.schres.2020.05.023 